\title{
Composição Corporal e Exigências Energéticas e Protéicas de Bovinos F1 Limousin $x$ Nelore, Não-Castrados, Alimentados com Rações Contendo Diferentes Níveis de Concentrado 1
}

\author{
Cristina Mattos Veloso², Sebastião de Campos Valadares Filho ${ }^{3}$, Antonio Gesualdi Júnior ${ }^{4}$, \\ Fabiano Ferreira da Silva ${ }^{2}$, Mário Fonseca Paulino ${ }^{3}$, Rilene Ferreira Diniz Valadares ${ }^{5}$, \\ Paulo Roberto Cecon ${ }^{6}$, Pedro Veiga Rodrigues Paulino ${ }^{7}$
}

RESUMO - Foram utilizados 50 novilhos F1 Limousin x Nelore inteiros, alocados em dez tratamentos, com cinco níveis de concentrado $(25 ; 37,5 ; 50 ; 62,5 ;$ e $75 \%)$ e duas formas de balanceamento protéico da dieta (uma isoprotéica com $12 \%$ de proteína bruta [PB] e outra variando proteína com energia). Avaliaram-se os consumos de matéria seca (MS), matéria orgânica (MO), PB, fibra em detergente neutro (FDN) e nutrientes digestíveis totais (NDT). Após o abate, todas as partes do corpo do animal foram pesadas, amostradas e analisadas para MS, teores de compostos nitrogenados totais e extrato etéreo. Os conteúdos de proteína, gordura e energia retidos no corpo foram estimados por meio de equações de regressão do logaritmo do conteúdo corporal de proteína, gordura ou energia, em função do logaritmo do peso de corpo vazio (PCVZ). As exigências líquidas de proteína e energia, para ganho de $1 \mathrm{~kg}$ de PCVZ foram obtidas a partir da equação Y=b. $10^{\mathrm{a}}$. $\mathrm{X}^{\mathrm{b}-1}$, sendo a e b o intercepto e o coeficiente de regressão, respectivamente, das equações de predição dos conteúdos corporais de proteína ou energia. A exigência líquida de energia para mantença $(E L m)$ foi estimada como o anti-log do intercepto da equação obtida pela regressão linear entre o logaritmo da produção de calor e o consumo de energia metabolizável. A forma de balanceamento da dieta não influenciou os consumos dos nutrientes. O consumo de MS, em kg/dia, não foi influenciado pelo nível de concentrado (NC), apresentando média de $7,39 \mathrm{~kg} / \mathrm{dia}$. O NC das dietas não influenciou o consumo de MO (7,08 kg/dia). Com o aumento do NC, o consumo de FDN reduziu e o de NDT aumentou linearmente. Nas dietas com níveis de proteína variados, o consumo de PB aumentou linearmente. Já as dietas isoprotéicas não foram influenciadas pelo $\mathrm{NC}$, apresentando média de consumo de $\mathrm{PB}$ de $0,89 \mathrm{~kg} / \mathrm{dia}$. As exigências de energia líquida para ganho de peso de bovinos F1 Limousin x Nelore não-castrados, em Mcal/kg, podem ser obtidas pela equação: $\mathrm{ELg}=0,038 \times \mathrm{PCVZ}^{0,75} \times \mathrm{GDPCVZ}^{0,9896}$ A ELm para estes animais foi de $76,36 \mathrm{kcal} / \mathrm{PCVZ}^{0,75}$. Foi obtida a seguinte equação para estimativa da proteína retida (PR), em g/dia, em função do ganho de PV em jejum (GPVJ), em kg/dia: PR = 174,14524 x GPVJ.

Palavras-chave: consumo, energia, mestiços, níveis de concentrado, proteína, requisitos nutricionais

\section{Body Composition and Energy and Protein Requirements of F1 Limousin $x$ Nellore Bulls Fed Diets with Different Concentrate Levels}

\begin{abstract}
Fifty F1 Limousin x Nellore bulls were allotted to ten treatments, with five concentrate levels (25, 37.5, 50, 62.5, and 75\%) and two diet protein balance methods (one isoprotein and the other changing protein as diet energy changed). The intake of dry matter (DM), organic matter $(\mathrm{OM})$, crude protein $(\mathrm{CP})$, neutral detergent fiber(NDF) and total digestible nutrients (TDN) were determined. After the slaughter, all animal body parts were weighed, sampled and DM, total nitrogen and ether extract concentrations were determined. Protein, fat and energy contents retained in the body were estimated by regression equations of logarithm of protein, fat or energy body content, as a function of logarithm of empty body weight (EBW). By deriving the prediction equations of body content of protein, fat, or energy, as a function of the logarithm of EBW, the net requirements of protein and energy, for gain of $1 \mathrm{~kg}$ EBW, were determined. The deriving equation was $\mathrm{Y}=\mathrm{b} \cdot 10^{\mathrm{a}}$. $\mathrm{X}^{\mathrm{b}-1}$, where a and $\mathrm{b}$ were the intercept and regression coefficient, respectively, of the prediction equations of protein or energy body contents. Net energy requirement for maintenance (NEm) was estimated as the intercept anti-log of the equation obtained by the linear regression of the logarithm of heat production and the metabolizable energy intake. The diet balance methods did not influence the nutrients intakes. The DM intake (DMI) was not affected by the concentrate level (CL), with means of $7.39 \mathrm{~kg} /$ day. Dietary CL did not affect OM intake (7.08 kg/day). Increasing CL and NDF intake showed a linear decrease and TDN intake showed a linear increase. In diets with variable protein levels, CP intake increased linearly. Isoprotein diets were not affected by the CL ( $0.89 \mathrm{~kg} /$ day). Net energy requirement for weight gain of F1 Limousin x Nellore bulls, in Mcal $/ \mathrm{kg}$, can be obtained by the equation: $\mathrm{NEg}=0.038 \times \mathrm{EBW}^{0.75} \mathrm{x}$ EBW gain ${ }^{0.9896}$. The NEm for these animals was $76.36 \mathrm{kcal} / \mathrm{EBW}^{0.75}$. The following equation was obtained to estimate the retained protein (RP), in g/day, as a function of EBW gain, in kg/day: RP = 174.14524 x EBW gain.
\end{abstract}

Key Words: concentrate levels, crossbred, energy, intake, nutritional requirements, protein

\footnotetext{
1 Parte da tese de Doutorado em Zootecnia apresentada pela primeira autora à UFV. Financiada pela FAPEMIG.

2 Professor(a) do curso de Zootecnia - UESB - Itapetinga, BA. E.mail: cmveloso@uesb.br; ffsilva@uesb.br

${ }^{3}$ Professor do Departamento de Zootecnia - UFV - Viçosa, MG. Bolsista do CNPq. E.mail: svcfilho@ufv.br; mpaulino@mail.ufv.br

${ }^{4}$ Estudante de Doutorado em Zootecnia - UFV - Viçosa, MG. E.mail: anaton@vicosa.com.br

5 Professora do Departamento de Medicina Veterinária - UFV - Viçosa, MG. Bolsista do CNPq. E.mail: rilene@mail.ufv.br

${ }^{6}$ Professor do Departamento de Matemática - UFV - Viçosa, MG. E.mail: cecon@dpi.ufv.br

${ }^{7}$ Mestrando em Zootecnia UFV - Viçosa, MG. E.mail: eg35439@correio.ufv.br
} 


\section{Introdução}

Sistemas auto-sustentáveis de produção animal, nos quais a dieta é baseada em volumosos, têm como principal fator limitante do nível e da eficiência de produção o consumo voluntário, o qual é considerado o principal determinante do consumo de nutrientes digestíveis e da eficiência com que tais nutrientes são utilizados nos processos metabólicos do animal (Ospina \& Prates, 1998) para o atendimento de suas exigências para mantença e produção, ou seja, é o fator que mais influencia o desempenho animal.

O crescimento, em tamanho e peso, de bovinos e a mudança correspondente na forma e na composição corporais são, de acordo com Robelin \& Geay (1984), de grande significado econômico. Segundo McDonald et al. (1995), o peso é o principal determinante da composição corporal e das exigências nutricionais para crescimento.

À medida que o peso do corpo vazio (PCVZ) aumenta, os pesos de todos os constituintes químicos elevam-se, mas a taxas diferentes. A gordura é depositada a uma taxa crescente e os componentes do corpo magro (representado pela proteína), a taxas decrescentes. O conteúdo energético do corpo segue uma curva semelhante àquela do conteúdo de gordura, porque, à medida que o animal cresce, a composição de seu ganho de PCVZ (GPCVZ) se modifica. No início da vida, os ganhos consistem, principalmente, de água, proteína e minerais (cinzas), necessários para o crescimento dos ossos e dos músculos; após, os ganhos contêm aumentada proporção de gordura e, como resultado, seu conteúdo de energia aumenta (McDonald et al., 1995).

O verdadeiro determinante da composição dos ganhos não é o peso corporal absoluto, mas o peso relativo ao peso à maturidade do grupo genético do qual o animal procede. Esta teoria é sustentada pelos efeitos do sexo sobre a composição dos ganhos. As fêmeas são menores que os machos, à maturidade, e, a um mesmo peso, depositam mais gordura e energia. Os animais castrados tendem a ser intermediários entre os machos inteiros e as fêmeas (McDonald et al., 1995). Segundo o ARC (1980), os machos inteiros têm maior exigência para mantença que os castrados e as fêmeas, porém seus ganhos têm menor conteúdo energético.

As exigências para mantença podem ser definidas como a combinação de nutrientes necessários para o animal manter seu corpo sem ganho ou perda de peso ou outra atividade produtiva. Os nutrientes absorvidos são utilizados para funções essenciais, como metabolismo corporal, manutenção da temperatura corporal e substituição e reparo de células e tecidos corporais (Ensminger et al., 1990).

Machos jovens ganham mais rapidamente e têm maior exigência para mantença do que fêmeas jovens. Segundo o ARC (1980), o CSIRO (1990) e o NRC (1996), as exigências de energia líquida para mantença (ELm) de machos castrados e novilhas são semelhantes, enquanto as de touros, $15 \%$ maiores.

Lofgreen \& Garrett introduziram o sistema de energia líquida para crescimento e engorda de gado de corte (Lofgreen \& Garrett, 1968), que separa as exigências de energia líquida em mantença e ganho de peso (crescimento e engorda). A soma das necessidades de mantença e ganho representa as exigências líquidas de energia dos animais. Conhecendo-se as exigências líquidas e levando-se em consideração os fatores de eficiência de utilização da energia dietética para mantença e ganho, obtêm-se as exigências de energia metabolizável.

O valor de $77 \mathrm{kcal} / \mathrm{kg} \mathrm{PV} \mathrm{P}^{0,75} / \mathrm{dia}$, obtido por Lofgreen \& Garrett (1968), foi adotado pelo NRC (1984 e 1996) como a exigência de ELm de bovinos de corte, tanto para fêmeas, quanto para machos.

Segundo o NRC (1996), a energia líquida para ganho (ELg) é o conteúdo de energia depositada nos tecidos, que é uma função da proporção de gordura e de proteína no GPCVZ. Entre bovinos com tamanhos semelhantes à maturidade, 95,6 a 98,9\% da variação nos componentes químicos e no conteúdo de energia do corpo vazio estão associados com a variação de peso.

Fontes (1995), analisando, conjuntamente, os dados de experimentos conduzidos com bovinos F1 Limousin $x$ Nelore, F1 Marchigiana x Nelore, F1 Angus x Nelore e F1 Holandês x Nelore não-castrados, encontrou valores de exigências de ELg, para animais de $450 \mathrm{~kg}$ de PCVZ, de 4,3 Mcal/kg de GPCVZ.

A quantidade de compostos nitrogenados $(\mathrm{N})$ necessária para mantença é definida, por McDonald et al. (1995), como aquela que equilibra as perdas fecais metabólicas e urinárias endógenas de $\mathrm{N}$ e, também, as pequenas perdas dermais de $\mathrm{N}$ que ocorrem na descamação, nos pêlos e no suor.

O INRA (1988), utilizando resultados de estudos de balanço de $\mathrm{N}$ que incluíam descamações e perdas metabólicas, urinárias e fecais, determinou que a exigência de proteína metabolizável para mantença é de $3,25 \mathrm{~g} / \mathrm{kg} \mathrm{PCVZ}^{0,75} /$ dia. Smuts (1935) calculou

R. Bras. Zootec., v.31, n.3, p.1273-1285, 2002 
esta mesma exigência em $3,52 \mathrm{~g} / \mathrm{kg} \mathrm{PV} 0,75 /$ dia. Wilkerson et al. (1993) estimaram as exigências de proteína metabolizável para mantença em $3,8 \mathrm{~g} / \mathrm{kg}$

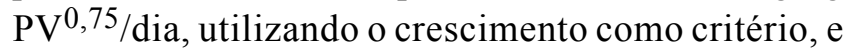
não o balanço de N. Este foi o motivo que fez com que o NRC (1996) adotasse este valor.

Para as exigências de PLg de bovinos Nelore, Marchigiana $x$ Nelore e Limousin $x$ Nelore nãocastrados, com PCVZ de 400 e $450 \mathrm{~kg}$, Pires et al. (1993) encontraram valores de 194 e $193 \mathrm{~g} / \mathrm{kg}$ de GPCVZ, respectivamente.

Já as exigências de proteína metabolizável (PM) são obtidas pela relação entre as exigências líquidas e a eficiência de utilização da proteína. O AFRC (1993) preconizou a eficiência de utilização da proteína metabolizável para ganho de peso em 59\%. Já o NRC (1996), considerando que a eficiência de utilização da PM varia de acordo com o PV, padronizou uma equação para estimativa da eficiência de utilização da PM para bovinos com peso vivo menor que $300 \mathrm{~kg}$ e, para animais com peso vivo maior que $300 \mathrm{~kg}$, preconizou esta eficiência em 49,2\%.

Os objetivos do presente trabalho foram determinar a composição corporal e as exigências de energia e proteína de animais $\mathrm{F} 1$ Limousin x Nelore nãocastrados, alimentados com rações contendo diferentes níveis de concentrado.

\section{Material e Métodos}

O experimento foi conduzido no Departamento de Zootecnia da Universidade Federal de Viçosa, em Viçosa-MG. Foram utilizados 50 novilhos F1 Limousin x Nelore, não-castrados, com peso vivo médio inicial de $330 \mathrm{~kg}$, confinados em baias individuais, com piso de concreto, providas de comedouro e bebedouro de concreto, com área total de $30 \mathrm{~m}^{2}$, sendo $8 \mathrm{~m}^{2}$ cobertos. Os animais passaram por um período de adaptação de 45 dias, durante o qual todos foram identificados, tratados contra ecto e endoparasitas e receberam a mesma dieta.

Cinco novilhos foram abatidos após o período de adaptação (grupo referência), servindo de referência nos estudos subseqüentes. Cinco novilhos foram alimentados com uma dieta contendo feno de capimCoastcross (Cynodon dactylon) (grupo mantença), para atender às exigências energéticas para mantença. Os 40 animais restantes foram pesados e distribuídos em dez tratamentos, com cinco níveis de concentrado nas dietas, quais sejam: $25 ; 37,5 ; 50 ; 62,5 ; \mathrm{e} 75 \%$ e duas formas de balanceamento protéico da dieta (uma isoprotéica com 12\% de proteína bruta e outra variando proteína e energia), em esquema fatorial $5 \times 2$ (cinco níveis de concentrado $\mathrm{x}$ duas formas de balanceamento protéico), em um delineamento inteiramente casualizado, com quatro repetições por tratamento. O volumoso consistiu de feno de capimCoastcross (Cynodon dactylon). Em cada grupo, quatro animais foram alimentados com rações formuladas com o intuito de serem isoprotéicas, com, aproximadamente, $12 \%$ de PB na MS, de acordo com o NRC (1996), nível um, e quatro animais foram alimentados com rações formuladas de acordo com o NRC (1996), nível dois, que não foram isoprotéicas.

Para o feno de Coastcross, os teores de MS (\%), fibra em detergente neutro (FDN, \% MS), lignina (\% MS), PB (\% MS), proteína solúvel (\% PB), nitrogênio não protéico (\% proteína solúvel), proteína insolúvel em detergente neutro $(\% \mathrm{~PB})$, proteína insolúvel em detergente ácido (\% PB), amido (\% carboidratos não-estruturais), extrato etéreo (EE, \% MS), cinzas (\% MS), FDN efetiva (\% FDN) e as taxas de digestão das frações $A, B_{1}$ e $B_{2}$ dos carboidratos e das frações $\mathrm{B}_{1}$, $\mathrm{B}_{2}$ e $\mathrm{B}_{3}$ da proteína foram, respectivamente, 88,$88 ; 80,00 ; 9,07 ; 9,00 ; 29,76 ; 94,28 ; 55,21$; 11,$24 ; 6 ; 1,34 ; 5,03 ; 98 ; 250 ; 30 ; 2,87 ; 43,12 ; 5,08$; e 0,23 . Para o milho utilizado no concentrado, foram 89,$02 ; 10,88 ; 12,50 ; 8,40 ; 15,81 ; 72,80 ; 8,74 ; 0,93 ; 90$; 5,$83 ; 1,12 ; 60 ; 150 ; 15 ; 5,00 ; 50,18 ; 2,94 ;$ e 0,23 e para o farelo de soja, 88,$71 ; 15,80 ; 28,48 ; 49,50 ; 28,33$; 29,$15 ; 3,56 ; 1,38 ; 90 ; 4,75 ; 6,02 ; 23 ; 300 ; 25 ; 6,00$; 283,$24 ; 8,24$; e 0,41 . A proporção dos ingredientes nas misturas de concentrados é apresentada na Tabela 1; os teores de nutrientes dos concentrados e do feno, na Tabela 2; e a composição bromatológica das dietas, na Tabela 3.

$\mathrm{O}$ alimento foi fornecido à vontade, uma vez ao dia, e ajustado de forma a manter as sobras entre $5 \mathrm{e}$ $10 \%$ do fornecido, com água permanentemente à disposição dos animais. A quantidade de ração oferecida foi registrada diariamente e, semanalmente, foram coletadas amostras do feno e dos concentrados, por tratamento, e das sobras, por animal. As amostras semanais de sobras foram agrupadas, de forma proporcional, em cada período de 28 dias, constituindo-se em amostras compostas, as quais foram pré-secas a $65^{\circ} \mathrm{C}$, em estufa ventilada, e processadas em moinho com peneira de malha de $1 \mathrm{~mm}$, para posteriores análises laboratoriais. Foram estudados os consumos de matéria seca, matéria orgânica, proteína bruta,

R. Bras. Zootec., v.31, n.3, p.1273-1285, 2002 
Tabela 1 - Composição dos concentrados, na base da matéria natural Table 1 - Concentrates composition, as fed basis

\begin{tabular}{|c|c|c|c|c|c|c|c|c|c|c|}
\hline Níveis de concentrado & & & & & & & & & & \\
\hline $\begin{array}{l}\text { Balanceamento protéico } \\
\text { Protein balance }\end{array}$ & 1 & 2 & 1 & 2 & 1 & 2 & 1 & 2 & 1 & 2 \\
\hline $\begin{array}{l}\text { Milho }(\%) \\
\text { Corn }\end{array}$ & 75,71 & 75,74 & 84,14 & 78,64 & 88,38 & 80,09 & 90,81 & 80,75 & 92,44 & 81,39 \\
\hline $\begin{array}{l}\text { Farelo de soja (\%) } \\
\text { Soybean meal }\end{array}$ & 21,14 & 22,62 & 13,24 & 19,65 & 9,24 & 18,13 & 6,93 & 17,43 & 5,41 & 16,76 \\
\hline $\begin{array}{l}\text { Uréia }(\%) \\
\text { Urea }\end{array}$ & 1,51 & 0,00 & 1,21 & 0,30 & 1,07 & 0,46 & 0,99 & 0,55 & 0,91 & 0,61 \\
\hline $\begin{array}{l}\text { Calcário }(\%) \\
\text { Limestone }\end{array}$ & 0,00 & 0,00 & 0,33 & 0,33 & 0,50 & 0,50 & 0,62 & 0,62 & 0,70 & 0,70 \\
\hline $\begin{array}{l}\text { Fosfato bicálcico }(\%) \\
\text { Dicalcium phosphate }\end{array}$ & 0,82 & 0,82 & 0,54 & 0,54 & 0,41 & 0,41 & 0,33 & 0,33 & 0,27 & 0,27 \\
\hline $\begin{array}{l}\text { Cloreto de sódio (\%) } \\
\text { Sodium chloride }\end{array}$ & 0,77 & 0,77 & 0,51 & 0,51 & 0,38 & 0,39 & 0,30 & 0,30 & 0,26 & 0,26 \\
\hline $\begin{array}{l}\text { Premix mineral }(\mathrm{g} / 100 \mathrm{~kg})^{1} \\
\text { Mineral premix }\end{array}$ & 59,00 & 59,00 & 39,29 & 39,29 & 29,44 & 29,44 & 23,58 & 23,58 & 19,62 & 19,62 \\
\hline
\end{tabular}

${ }^{1}$ Isoprotéica (Isoprotein).

2 Proteína variável (Variable protein).

${ }^{1}$ Composição (Composition): sulfato de zinco (zinc sulfate), 80,02\%; sulfato de cobre (cupper sulfate), 18,96\%; iodato de potássio (potassium iodate), $0,51 \%$; sulfato de cobalto (cobalt sulfate), $0,255 \%$; selenito de sódio (sodium selenite), $0,255 \%$.

Tabela 2 - Teores médios de matéria seca (MS), matéria orgânica (MO), proteína bruta (PB), extrato etéreo (EE), carboidratos totais $(\mathrm{CHO})$, fibra em detergente neutro (FDN), carboidratos não-fibrosos (CNF), cálcio (Ca) e fósforo $(P)$ dos concentrados e do feno de capim-coastcross

Table 2 - Average contents of dry matter (DM), organic matter (OM), crude protein (CP), ether extract (EE), total carbohydrates $(C H O)$, neutral detergent fiber (NDF), non fiber carbohydrates (NFC), calcium (Ca) and phosphorus ( $P$ ) of the concentrates and coastcross hay

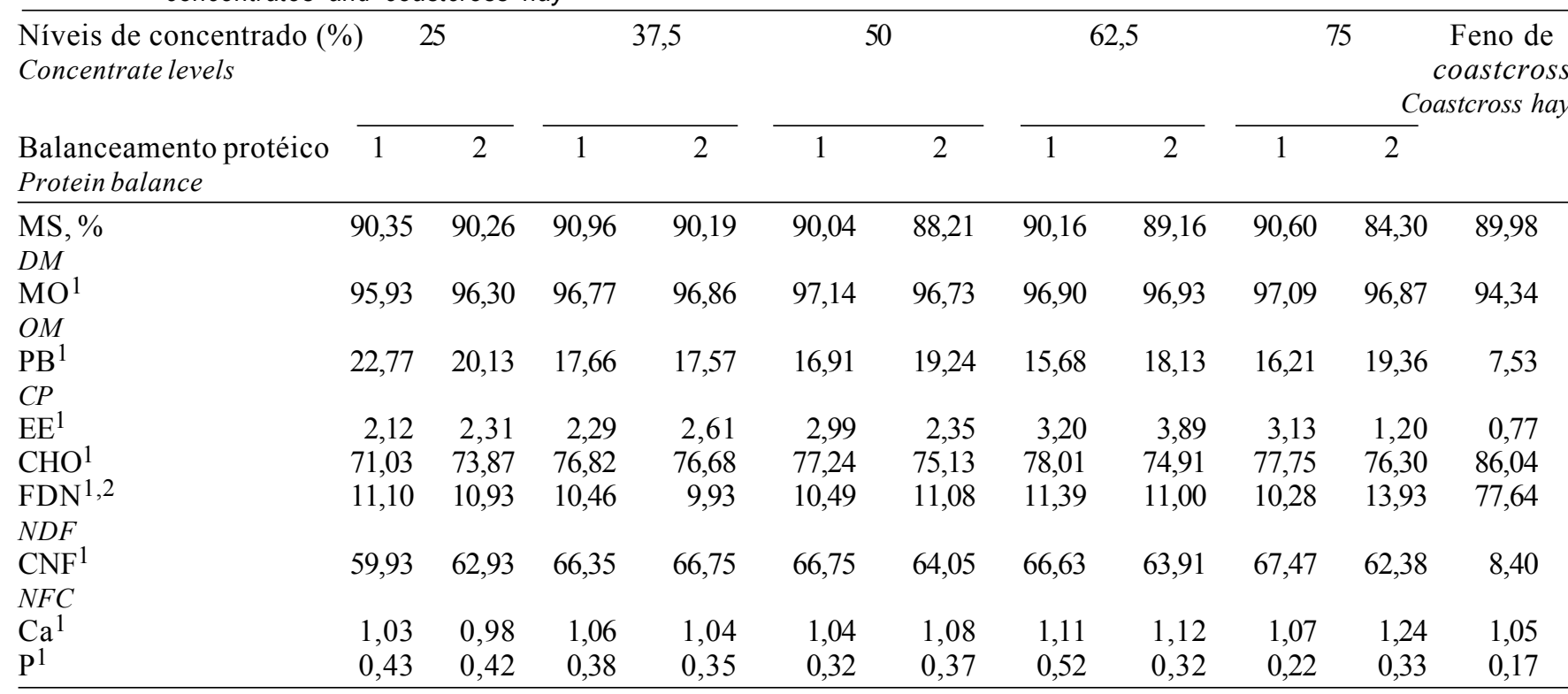

${ }^{1}$ Isoprotéico (Isoprotein).

2 Proteína variada (Variable protein).

1 Porcentagem na MS (Percentage in DM).

2 FDN corrigida para proteína e cinzas (NDF corrected for protein and ash). 
Tabela 3 - Teores médios de matéria seca $(M S)$, matéria orgânica (MO), proteína bruta (PB), extrato etéreo (EE), carboidratos totais (CHO), fibra em detergente neutro (FDN), carboidratos não-fibrosos (CNF), nutrientes digestíveis totais (NDT), cálcio (Ca) e fósforo $(\mathrm{P})$ das dietas experimentais

Table 3 - Average contents of dry matter (DM), organic matter (OM), crude protein (CP), ether extract (EE), total carbohydrates (CHO), neutral detergent fiber (NDF), non fiber carbohydrates (NFC), total digestible nutrients (TDN), calcium (Ca) and phosphorus $(P)$ of the experimental diets

\begin{tabular}{|c|c|c|c|c|c|c|c|c|c|c|}
\hline \multirow{2}{*}{$\begin{array}{l}\text { Níveis de concentrado } \\
\text { na dieta }(\%) \\
\text { Concentrate levels in the diet } \\
\text { Balanceamento protéico } \\
\text { Protein balance }\end{array}$} & \multicolumn{2}{|c|}{25} & \multicolumn{2}{|c|}{37,5} & \multicolumn{2}{|c|}{50} & \multicolumn{2}{|c|}{62,5} & \multicolumn{2}{|c|}{75} \\
\hline & 1 & 2 & 1 & 2 & 1 & 2 & 1 & 2 & 1 & 2 \\
\hline $\begin{array}{l}\mathrm{MS}, \% \\
D M\end{array}$ & 90,08 & 90,05 & 90,34 & 90,06 & 90,01 & 89,09 & 90,09 & 89,47 & 90,45 & 85,72 \\
\hline $\begin{array}{l}\mathrm{MO}^{1} \\
O M\end{array}$ & 94,73 & 94,83 & 95,25 & 95,28 & 95,74 & 95,53 & 95,94 & 95,96 & 96,40 & 96,23 \\
\hline $\begin{array}{l}\mathrm{PB}^{1} \\
C P\end{array}$ & 11,34 & 10,68 & 11,33 & 11,29 & 12,22 & 13,39 & 12,62 & 14,16 & 14,04 & 16,40 \\
\hline $\begin{array}{l}\mathrm{EE}^{1} \\
\mathrm{CHO}^{1} \\
\mathrm{FDN}^{1,2}\end{array}$ & $\begin{array}{r}1,11 \\
82,29 \\
68,51\end{array}$ & $\begin{array}{r}1,16 \\
82,99 \\
68,40\end{array}$ & $\begin{array}{r}1,34 \\
82,58 \\
61,81\end{array}$ & $\begin{array}{r}1,46 \\
82,53 \\
61,60\end{array}$ & $\begin{array}{l}1 \\
81,64 \\
54,12\end{array}$ & $\begin{array}{r}81,56 \\
80,58 \\
54,61\end{array}$ & $\begin{array}{r}2,29 \\
81,03 \\
45,59\end{array}$ & $\begin{array}{r}2,72 \\
79,08 \\
45,55\end{array}$ & $\begin{array}{r}2,54 \\
79,82 \\
34,74\end{array}$ & $\begin{array}{r}1,09 \\
78,74 \\
37,09\end{array}$ \\
\hline $\begin{array}{l}N D F \\
\mathrm{CNF}^{1} \\
N F C\end{array}$ & 13,78 & 14,59 & 20,77 & 20,93 & 27,52 & 25,97 & 35,44 & 33,53 & 45,09 & 41,65 \\
\hline $\begin{array}{l}\mathrm{NDT} \\
T D N\end{array}$ & $55,87^{4}$ & $51,15^{3}$ & $59,55^{4}$ & $56,13^{3}$ & $67,17^{4}$ & $58,78^{3}$ & $66,97^{4}$ & $66,88^{3}$ & $76,40^{4}$ & $72,76^{3}$ \\
\hline $\begin{array}{l}\mathrm{Ca}^{1} \\
\mathrm{P}^{1}\end{array}$ & $\begin{array}{l}1,04 \\
0,23\end{array}$ & $\begin{array}{l}1,03 \\
0,23\end{array}$ & $\begin{array}{l}1,05 \\
0,24\end{array}$ & $\begin{array}{l}1,04 \\
0,23\end{array}$ & $\begin{array}{l}1,05 \\
0,24\end{array}$ & $\begin{array}{l}1,06 \\
0,27\end{array}$ & $\begin{array}{l}1,09 \\
0,39\end{array}$ & $\begin{array}{l}1,09 \\
0,26\end{array}$ & $\begin{array}{l}1,07 \\
0,20\end{array}$ & $\begin{array}{l}1,20 \\
0,28\end{array}$ \\
\hline
\end{tabular}

${ }^{1}$ Isoprotéico (Isoprotein).

2 Proteína variada (Variable protein)

1 Porcentagem na MS (Percentage in DM).

${ }^{2}$ FDN corrigida para proteína e cinzas (NDF corrected for protein and ash).

3 Dias et al. (2000).

${ }^{4}$ Cardoso et al. (2000).

fibra em detergente neutro e nutrientes digestíveis totais, por nível de concentrado e por forma de balanceamento protéico da dieta.

Os animais foram pesados no início do experimento e, periodicamente, a cada 28 dias. À medida que um animal se aproximava do peso de abate pré-estabelecido, $500 \mathrm{~kg}$, era pesado a intervalos menores. Antes do abate, os animais foram submetidos a um jejum de 16 horas. Após o abate, o trato gastrintestinal foi esvaziado e lavado. Após escorrimento da água de lavagem, o trato gastrintestinal, bem como todas as outras partes do corpo do animal, foi pesado para obtenção do PCVZ final. A relação obtida entre o PCVZ e o PV dos animais referência foi utilizada para a estimativa do PCVZ inicial dos animais que permaneceram no experimento. Dentro de cada tratamento, foisorteado, aleatoriamente, um animal para representá-lo, do qual foram retiradas amostras da cabeça e de um membro anterior e de outro posterior, para, em seguida, proceder-se à separação física de músculos, gordura, ossos e couro.
As amostras de sangue foram coletadas imediatamente após o abate, acondicionadas em recipientes de vidro e levadas à estufa com ventilação forçada, a $55-60^{\circ} \mathrm{C}$, durante 48 a 72 horas, para determinação do teor de matéria seca (MS). A seguir, foram processadas em moinho de bola e acondicionadas em recipientes apropriados, para posteriores análises de nitrogênio total e extrato etéreo, conforme AOAC (1980), sendo que o teor de proteína foi obtido pelo produto entre o teor de nitrogênio total e o fator 6,25 .

A carcaça de cada animal foi dividida em duas meias-carcaças, as quais foram pesadas e, em seguida, resfriadas em câmara fria $\mathrm{a}-5^{\circ} \mathrm{C}$, durante 18 horas. Decorrido este tempo, as meias-carcaças foram retiradas da câmara fria, sendo colhida e pesada uma amostra da meia-carcaça esquerda, correspondente à seção entre a $9^{\mathrm{a}}$ e $11^{\mathrm{a}}$ costelas (seção $\mathrm{HH}$ ), para posteriores dissecação e predição das proporções de músculos, ossos e tecido adiposo na carcaça, segundo equações preconizadas por Hankins \& Howe (1946):

Proporção de músculo: $\mathrm{Y}=16,08+0,80 \mathrm{X}$; 
Proporção de tecido adiposo: $\mathrm{Y}=3,54+0,80 \mathrm{X}$;

Proporção de ossos: $\mathrm{Y}=5,52+0,57 \mathrm{X}$.

em que: $\mathrm{X}=$ porcentagem dos componentes na seção $\mathrm{HH}$.

As amostras de rúmen, retículo, omaso, abomaso, intestino delgado, intestino grosso, gordura interna, mesentério e aparas (esôfago, traquéia e aparelho reprodutor) foram agrupadas de forma proporcional e constituíram uma amostra composta de vísceras, enquanto as de fígado, coração, rins, pulmões, língua, baço e carne industrial, agrupadas também de forma proporcional, compuseram a amostra de órgãos.

Excetuando-se as amostras de sangue, as amostras compostas de órgãos ( $200 \mathrm{~g})$ e de vísceras $(200 \mathrm{~g})$, músculos (200 g) e gordura (200 g), após moídas, e as de couro (100 g), ossos (100 g) e cauda (100 g), após seccionadas, foram acondicionadas em vidros com capacidade de $500 \mathrm{~mL}$ e levadas à estufa a $105^{\circ} \mathrm{C}$, por um período de 48 a 96 horas, dependendo da amostra, para determinação da matéria seca gordurosa (MSG).

Posteriormente, procedeu-se ao desengorduramento das referidas amostras, com lavagens sucessivas com éter de petróleo, obtendo-se a matéria seca pré-desengordurada (MSPD). Em seguida, as amostras foram processadas em moinho de bola, para posteriores determinações de nitrogênio total e extrato etéreo. A gordura removida no pré-desengorduramento foi calculada como a diferença entre a MSG e a MSPD e adicionada aos resultados obtidos para o extrato etéreo residual na MSPD, para determinação do teor total de gordura. A partir do conhecimento dos teores de proteína e extrato etéreo na MSPD, e do peso da amostra submetida ao pré-desengorduramento, determinaram-se os respectivos teores na matéria natural.

Os conteúdos corporais de proteína e gordura foram determinados em função das concentrações percentuais destes nos órgãos, nas vísceras, no couro, no sangue, na cauda, na cabeça, nos pés e nos constituintes separados (gordura, músculos e ossos) da seção HH; estes últimos representaram a composição física da carcaça.

A determinação da energia corporal foi obtida a partir dos teores corporais de proteína e gordura e seus respectivos equivalentes calóricos, conforme a equação preconizada pelo ARC (1980):

$$
\mathrm{CE}=5,6405 \mathrm{X}+9,3929 \mathrm{Y}
$$

em que: $\mathrm{CE}=$ conteúdo energético $(\mathrm{Mcal}) ; \mathrm{X}=$ proteína corporal $(\mathrm{kg})$; e $\mathrm{Y}=$ gordura corporal $(\mathrm{kg})$.

Os conteúdos de proteína, gordura e energia retidos no corpo dos animais de cada tratamento, e para todos os tratamentos em conjunto, foram estimados por meio de equações de regressão do logaritmo do conteúdo corporal de proteína, gordura ou energia, em função do logaritmo do PCVZ, segundo o ARC (1980), conforme o seguinte modelo:

$$
\mathrm{Y}=\mathrm{a}+\mathrm{bX}+\mathrm{e}
$$

em que: $\mathrm{Y}=$ logaritmo do conteúdo total de proteína $(\mathrm{kg})$, gordura $(\mathrm{kg})$ ou energia (Mcal) retido no corpo vazio; $a=$ constante; $b=$ coeficiente de regressão do logaritmo do conteúdo de proteína, gordura, ou energia, em função do logaritmo do PCVZ; X = logaritmo do PCVZ; e e = erro aleatório.

Para cada tratamento, as equações foram construídas adicionando-se os valores relativos aos animais referência.

Derivando-se as equações de predição do conteúdo corporal de proteína, gordura ou energia, em função do logaritmo do PCVZ, foram obtidas as equações de predição dos conteúdos de proteína, gordura ou energia, por kg de ganho de PCVZ. As exigências líquidas de proteína e energia, para ganho de $1 \mathrm{~kg}$ de PCVZ, corresponderam aos respectivos conteúdos no ganho de corpo vazio e foram obtidas, juntamente com o conteúdo de gordura no ganho de corpo vazio, a partir de equação do tipo:

$$
\mathrm{Y}^{\prime}=\text { b. } 10^{\mathrm{a}} \cdot \mathrm{Xb}^{-1}
$$

em que: $\mathrm{Y}^{\prime}=$ conteúdo de gordura no ganho, ou exigência líquida de proteína ou energia; $a$ e $b=$ intercepto e coeficiente de regressão, respectivamente, das equações de predição dos conteúdos corporais de proteína, gordura ou energia; e $\mathrm{X}=$ PCVZ (kg).

As exigências de proteína metabolizável para mantença (PMm) e ganho (PMg) e as exigências de proteína bruta foram obtidas segundo o NRC (1996).

Para a conversão do PV em PCVZ, dentro do intervalo de pesos incluído no trabalho, calculou-se a correlação entre o PCVZ e o PV dos 40 animais mantidos no experimento. Para conversão das exigências para ganho de PCVZ em exigências para ganho de PV, utilizou-se o fator obtido a partir dos dados experimentais.

Foi efetuada uma equação de regressão entre a energia retida (ER) e o ganho diário de $\mathrm{PCVZ}$ (GDPCVZ), para determinado PCVZ, conforme preconizado pelo NRC (1984 e 1996).

A produção de calor em jejum ou as exigências líquidas de energia para mantença (ELm) foram estimadas como o anti-log do intercepto da equação

R. Bras. Zootec., v.31, n.3, p.1273-1285, 2002 
obtida pela regressão linear entre o logaritmo da produção diária de calor (PC) e o consumo diário de energia metabolizável (CEM), segundo Lofgreen \& Garrett (1968).

As determinações de matéria seca (MS), matéria orgânica (MO), nitrogênio total, extrato etéreo (EE), fibra em detergente neutro (FDN) e macroelementos minerais $(\mathrm{Ca}$ e $\mathrm{P}$ ) foram realizadas conforme técnicas descritas por Silva (1990), sendo que a proteína bruta (PB) foi obtida pelo produto entre o teor de nitrogênio total e o fator 6,25 . A solução mineral para determinação dos macroelementos minerais foi preparada por via úmida (Silva, 1990). Após as devidas diluições, o teor de $\mathrm{P}$ foi determinado por colorimetria e o de $\mathrm{Ca}$, em espectrofotômetro de absorção atômica. Os carboidratos não-fibrosos (CNF) foram obtidos pela relação $100-(\% \mathrm{~PB}+\% \mathrm{FDN}+\% \mathrm{EE}+\%$ Cinzas $)$, conforme recomendações de Hall (2001). Os valores de NDT das dietas foram obtidos por ensaio de digestibilidade, de acordo com Cardoso et al. (2000) e Dias et al. (2000), que utilizaram animais e dietas semelhantes aos do presente experimento.

Os resultados foram interpretados, estatisticamente, por meio de análises de variância e regressão, utilizando-se o Sistema de Análises Estatísticas e Genéticas - SAEG (Universidade Federal de Viçosa - UFV, 1995). O coeficiente de determinação ( $\mathrm{r}^{2}$, em \%) utilizado foi o ajustado. As comparações entre as equações de regressão dos parâmetros avaliados para cada tratamento foram realizadas de acordo com a metodologia recomendada por Regazzi (1996), para testar identidade de modelos.

\section{Resultados e Discussão}

$\mathrm{Na}$ Tabela 4, são apresentados os consumos médios diários de MS, MO, FDN e NDT, por nível de concentrado e por forma de balanceamento protéico da dieta.

A forma de balanceamento protéico da dieta não influenciou $(\mathrm{P}>0,01)$ os consumos dos nutrientes, qualquer que seja a forma de expressão considerada.

$\mathrm{O}$ consumo de MS, expresso em $\mathrm{kg} / \mathrm{dia}$, não foi influenciado $(\mathrm{P}>0,01)$ pelo nível de concentrado, apresentando média de 7,39. Quando o mesmo foi expresso em porcentagem do PV (\% PV) e em gramas por unidade de tamanho metabólico $\left(\mathrm{g} / \mathrm{kg}^{0,75}\right)$, demonstrou comportamento linear decrescente $(\mathrm{P}<0,01) \mathrm{em}$ relação ao nível de concentrado.

Segundo o NRC (1987), o consumo por unidade de peso metabólico começa a declinar próximo de 350 $\mathrm{kg}$ de peso, para um novilho de porte médio. $\mathrm{Na}$ Figura 1, pode-se visualizar este declínio, utilizandose os dados deste experimento, que demonstraram um efeito linear decrescente do PV sobre o consumo de MS.

Os níveis de concentrado das dietas não influenciaram $(\mathrm{P}>0,01)$ o consumo de $\mathrm{MO}$, que apresentou valor médio de $7,08 \mathrm{~kg} /$ dia, refletindo o comportamento verificado para a ingestão de $\mathrm{MS}$, em $\mathrm{kg} / \mathrm{dia}$.

O consumo de FDN, expresso em $\mathrm{kg} / \mathrm{dia}$ e em \% $\mathrm{PV}$, apresentou comportamento linear decrescente com o aumento do nível de concentrado, devido à redução da proporção de volumoso na dieta, ingrediente que contém altos teores de fibra.

A FDN constitui-se no melhor preditor químico da ingestão voluntária de MS, pois sua fermentação e passagem pelo rúmen-retículo são mais lentas que as dos constituintes não fibrosos da dieta, apresentando maior efeito de enchimento (Allen, 1996). Neste experimento, os teores de FDN da dieta não influenciaram $(\mathrm{P}>0,01)$ o consumo de MS, em $\mathrm{kg} / \mathrm{dia}$.

O consumo de NDT, em kg/dia, apresentou comportamento linear crescente com o aumento do nível de concentrado.

$\mathrm{O}$ consumo de proteína bruta $(\mathrm{PB})$, em $\mathrm{kg} / \mathrm{dia}$, está apresentado na Tabela 5 , decomposto em nível de concentrado por forma de balanceamento da dieta, devido à interação existente entre as duas variáveis.

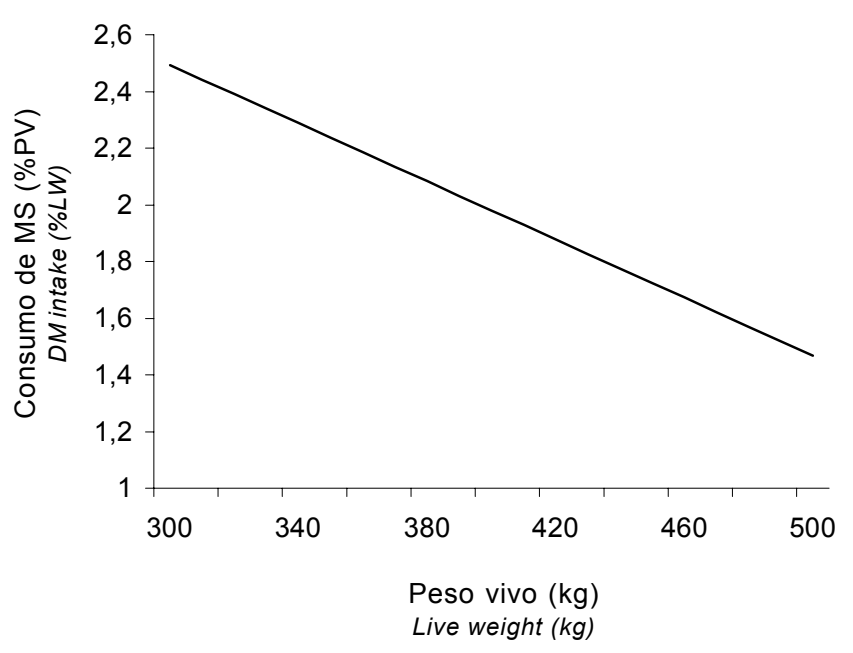

Figura 1 - Estimativa do consumo de matéria seca (MS), expresso em porcentagem do peso vivo, em função do peso vivo do animal, em $\mathrm{kg}$.

Figure 1 - Estimate of dry matter (DM) intake, express on live weight percentage, as function of animal live weight, in $\mathrm{kg}$.

R. Bras. Zootec., v.31, n.3, p.1273-1285, 2002 
Tabela 4 - Médias, equações de regressão (ER), coeficientes de determinação (r2) e coeficientes de variação (CV, \%) dos consumos diários de matéria seca (MS), matéria orgânica (MO), fibra em detergente neutro (FDN) e nutrientes digestíveis totais (NDT), em função dos níveis de concentrado (NC) e das formas de balanceamento protéico das dietas

Table 4 - Means, regression equations (RE), coefficients of determination ( $r 2)$ and coefficients of variation (CV) of daily contents of dry matter (DM), organic matter (OM), neutral detergent fiber (NDF) and total digestible nutrients (TDN), on the concentrate levels $(C L)$ and the protein balance forms of diets

\begin{tabular}{|c|c|c|c|c|c|c|c|c|c|}
\hline \multirow[b]{2}{*}{$\begin{array}{l}\text { Consumo } \\
\text { Intake }\end{array}$} & \multicolumn{5}{|c|}{$\begin{array}{l}\text { Níveis de concentrado na dieta }(\%) \\
\text { Concentrate levels in the diet }\end{array}$} & \multicolumn{2}{|c|}{$\begin{array}{c}\text { Balanceamento protéico } \\
\text { Protein balance }\end{array}$} & \multirow[b]{2}{*}{$\mathrm{ER}$} & \multirow[b]{2}{*}{$\mathrm{CV}(\%)$} \\
\hline & 25 & 37,5 & 50 & 62,5 & 75 & 1 & 2 & & \\
\hline $\begin{array}{l}\text { MS, } \mathrm{kg} / \mathrm{dia} \\
D M, \mathrm{~kg} / \mathrm{d}\end{array}$ & 7,51 & 7,66 & 7,52 & 7,24 & 7,04 & 7,27 & 7,52 & $\hat{\mathrm{Y}}=7,39$ & 6,71 \\
\hline $\begin{array}{l}\mathrm{MS}, \% \mathrm{PV} \\
D M, \% L W\end{array}$ & 1,88 & 1,91 & 1,85 & 1,76 & 1,72 & 1,79 & 1,85 & 1 & 5,40 \\
\hline $\begin{array}{l}\mathrm{MS}, \mathrm{g} / \mathrm{kg}^{0,75} \\
\mathrm{DM}, \mathrm{g} / \mathrm{kg}^{.75}\end{array}$ & 83,93 & 85,39 & 82,94 & 79,17 & 77,26 & 80,46 & 83,01 & 2 & 5,51 \\
\hline $\begin{array}{l}\mathrm{MO}, \mathrm{kg} / \mathrm{dia} \\
O M, \mathrm{~kg} / \mathrm{d}\end{array}$ & 7,13 & 7,31 & 7,20 & 6,96 & 6,80 & 6,96 & 7,20 & $\hat{\mathrm{Y}}=7,08$ & 6,79 \\
\hline $\begin{array}{l}\text { FDN, } \mathrm{kg} / \mathrm{dia} \\
N D F, \mathrm{~kg} / \mathrm{d}\end{array}$ & 5,04 & 4,50 & 3,77 & 2,98 & 2,37 & 3,66 & 3,80 & 3 & 5,80 \\
\hline $\begin{array}{l}\mathrm{FDN}, \% \mathrm{PV} \\
N D F, \% L W\end{array}$ & 1,26 & 1,12 & 0,93 & 0,72 & 0,58 & 0,91 & 0,94 & 4 & 4,48 \\
\hline $\begin{array}{l}\text { NDT, } \mathrm{kg} / \mathrm{dia} \\
T D N, \mathrm{~kg} / \mathrm{d}\end{array}$ & 4,02 & 4,44 & 4,73 & 4,84 & 5,24 & 4,72 & 4,59 & 5 & 6,78 \\
\hline \multicolumn{10}{|c|}{$\begin{array}{l}{ }_{1}^{1} \text { Isoprotéico (Isoprotein). } \\
2 \text { Proteína variada (Variable protein). }\end{array}$} \\
\hline \multicolumn{10}{|c|}{${ }^{1} \hat{Y}=2,00790-0,00373653^{* *} n c r^{2}=0,85$} \\
\hline \multicolumn{10}{|c|}{$2 \hat{Y}=89,5375-0,155987^{* *} n c r^{2}=0,83$} \\
\hline \multicolumn{10}{|c|}{${ }^{3} \hat{Y}=6,45824-0,0545215^{* *} n c r^{2}=0,99$} \\
\hline \multicolumn{10}{|c|}{${ }^{4} \hat{Y}=1,62078-0,0139861^{* *} n c r^{2}=0,99$} \\
\hline $\begin{array}{l}5 \hat{\mathrm{Y}}=3,51859 \\
{ }_{* *} \text { Significativc }\end{array}$ & $\begin{array}{l}0226927 \\
1 \% \mathrm{de} \mathrm{pr}\end{array}$ & $c r^{2}=0$ & tect & & & & & & \\
\hline
\end{tabular}

Os comportamentos observados foram os esperados, pois, nas dietas formuladas para conterem níveis de proteína variados, conforme o NRC (1996), nível dois, o consumo de $\mathrm{PB}$ apresentou resposta linear crescente. Já as dietas formuladas, segundo o NRC (1996), nível um, para serem isoprotéicas, não foram influenciadas pelo nível de concentrado, apresentando média de consumo de PB de 0,89 kg/dia. As formas de balanceamento protéico influenciaram o consumo de PB $(\mathrm{P}<0,01)$, quando o nível de concentrado na dieta foi superior a 50\%, com maiores consumos nas dietas contendo níveis variados de proteína, pois estas dietas apresentaram teores de PB mais elevados com a participação de concentrado acima de 50\% (Tabela 3 ), em comparação à dieta isoprotéica.

A relação obtida para estimativa do $\mathrm{PCVZ}$, a partir do PV dos animais utilizados no experimento, foi: $\mathrm{PCVZ}=\mathrm{PV} \times 0,8968$, semelhante às constantes 0,891 (NRC, 1996), 0,884 (Véras, 2000) e 0,8975 (Silva et al., 2001).

\footnotetext{
R. Bras. Zootec., v.31, n.3, p.1273-1285, 2002
}

Para conversão das exigências para ganho de PCVZ (GPCVZ) em exigências para ganho de PV (GPV), foi obtida a seguinte relação: GPCVZ $=1,02$ x GPV. Assim, nas condições do presente trabalho, para se obterem as exigências líquidas para ganho de $1 \mathrm{~kg}$ de PV, devem-se multiplicar as exigências para ganho de $1 \mathrm{~kg}$ de $\mathrm{PCVZ}$ pelo fator 1,02.

Os parâmetros das equações de regressão do logaritmo dos conteúdos de proteína $(\mathrm{kg})$, gordura $(\mathrm{kg})$ e energia (Mcal) no corpo vazio, em função do logaritmo do PCVZ, obtidos para cada nível de concentrado e para todos os níveis em conjunto, são apresentados na Tabela 6 . $\mathrm{O}$ teste de identidade entre os modelos, aplicado às equações de regressão, para os cinco níveis de concentrado na dieta, indicou não haver diferença entre os tratamentos. Portanto, pode-se recomendar o uso da equação conjunta, que é comum aos cinco níveis de inclusão de concentrado nas rações.

De acordo com as equações obtidas para os tratamentos em conjunto, observaram-se aumentos 
Tabela 5 - Médias, equação de regressão (ER), coeficiente de determinação e coeficientes de variação (CV, \%) para o consumo diário de proteína bruta (PB), em kg, em função dos níveis de concentrado (NC) e das formas de balanceamento protéico das dietas

Table 5 - Means, regression equations (RE), coefficients of determination $\left(r^{2}\right)$ and coefficients of variation (CV, \%) of daily crude protein $(C P)$ intake, in $\mathrm{kg}$, on the concentrate levels $(C L)$ and the protein balance forms of diets

\begin{tabular}{|c|c|c|c|c|c|c|c|}
\hline \multirow[b]{2}{*}{$\begin{array}{l}\text { Balanceamento protéico } \\
\text { Protein balance }\end{array}$} & \multicolumn{5}{|c|}{$\begin{array}{c}\text { Níveis de concentrado (\%) } \\
\text { Concentratelevels }\end{array}$} & \multirow[b]{2}{*}{ ER } & \multirow[b]{2}{*}{ CV $(\%)$} \\
\hline & 25 & 37,5 & 50 & 62,5 & 75 & & \\
\hline $\begin{array}{l}\text { Isoprotéico } \\
\text { Isoprotein }\end{array}$ & $0,83^{\mathrm{A}}$ & $0,87^{\mathrm{A}}$ & $0,90^{\mathrm{A}}$ & $0,90^{\mathrm{A}}$ & $0,96^{\mathrm{A}}$ & $\hat{\mathrm{Y}}=0,89$ & 5,31 \\
\hline $\begin{array}{l}\text { Proteína variada } \\
\text { Variable protein }\end{array}$ & $0,82^{\mathrm{A}}$ & $0,85^{\mathrm{A}}$ & $1,04^{\mathrm{A}}$ & $1,05^{\mathrm{A}}$ & $1,17^{\mathrm{A}}$ & 1 & 7,47 \\
\hline
\end{tabular}

Médias seguidas de uma mesma letra, na coluna, não diferenciam, a $1 \%$ de probabilidade, pelo teste $\mathrm{F}$.

Means followed by the same letter, within a column, do not differ at $1 \%$ of probability by $F$ test.

${ }^{1} \hat{\mathrm{Y}}=0,62764+0,00721556^{* *} n c \mathrm{r}^{2}=0,94$.

** Significativo a $1 \%$ de probabilidade, pelo teste "t" (Significant at $1 \%$ of probability by $t$ test).

no conteúdo corporal de proteína(de 59,72 para $94,32 \mathrm{~kg}$ ), gordura (de 29,44 para 76,29 kg), e energia (de 616,35 para 1260,24 Mcal), com aumento do PV dos animais de 300 para $500 \mathrm{~kg}$.

As exigências líquidas de proteína e energia e os conteúdos de gordura, por kg de ganho de PCVZ, são apresentados na Tabela 7. Para a conversão das exigências para ganho de PCVZ em exigências para ganho de $\mathrm{PV}$, basta multiplicar as primeiras pelo fator 1,02 , obtido neste trabalho.

Os conteúdos de gordura e energia no ganho de PCVZ aumentaram com a elevação do PV ou do PCVZ, pois, à medida que o peso corporal se eleva, a concentração de gordura aumenta (Berg \& Butterfield, 1976), com concomitante acréscimo nas exigências energéticas, já que o valor energético do ganho aumenta com a elevação do peso dos animais. Os valores obtidos para a variação de PV no intervalo de 300 a $500 \mathrm{~kg}$ foram menores que os relatados por Fontes (1995), em compilação de vários trabalhos de exigências nutricionais de animais mestiços Limousin x Nelore, Marchigiana x Nelore, Angus x Nelore e Holandês x Nelore não-castrados, em conjunto. No entanto, o conteúdo de gordura foi maior que o observado por Ferreira et al. (1999), para bovinos F1 Simental x Nelore não-castrados, até $400 \mathrm{~kg}$ de PV, e a exigência líquida de energia para ganho de $1 \mathrm{~kg}$ de PCVZ foi maior até $450 \mathrm{~kg}$ de PV. Para $500 \mathrm{~kg}$ de $\mathrm{PV}$, a exigência de energia líquida para ganho (ELg) foi semelhante para os animais Limousin $\mathrm{x}$ Nelore (3,94 Mcal/kg de GPCVZ) e os Simental x Nelore (3,96 Mcal/kg de GPCVZ).

As exigências líquidas de proteína decresceram, à medida que o PV dos animais aumentou, devido à maior concentração de gordura, em detrimento à de proteína, caracterizando menor ganho de proteína por kg de ganho de PCVZ. Segundo Grant \& Helferich (1991), isto se deve à desaceleração do crescimento muscular e ao desenvolvimento mais rápido do tecido adiposo, com a elevação do peso do animal.

As exigências líquidas de proteína para ganho de $1 \mathrm{~kg}$ de PCVZ foram inferiores às apresentadas por Pires et al. (1993) para os PV de 350 a $500 \mathrm{~kg}$ e superiores para $300 \mathrm{~kg}$ de PV. Entretanto, foram mais elevadas que as relatadas por Fontes (1995), Freitas (1995), Estrada et al. (1997) e Ferreira et al. (1999), que utilizaram bovinos mestiços não-castrados.

Utilizando-se os dados do presente trabalho, foi obtida a seguinte equação para estimativa da proteína retida (PR), em g/dia, em função do ganho de peso vivo em jejum (GPVJ), em kg/dia: $P R=174,14524 x$ GPVJ. O NRC (1996) preconiza a equação $\mathrm{PR}=$ GPVJ $(268-(29,4($ ER/GPVJ $)))$ para estimativa das exigências líquidas de proteína para ganho (PR). Utilizando a equação deste experimento e considerando um bovino de $500 \mathrm{~kg}$ de PV, com ganho diário de PV de $1 \mathrm{~kg}$, obtém-se retenção líquida diária de proteína de 174,15 g. Substituindo na equação do NRC (1996) o valor da ER para o mesmo animal citado, de acordo com a equação de ER, em função do PCVZ e do ganho de PCVZ, descrita neste trabalho, de 3,72 Mcal/dia, obtém-se uma retenção líquida diária de proteína de $158,63 \mathrm{~g}$, valor $8,9 \%$ menor que o estimado neste experimento.

$\mathrm{Na}$ Tabela 8, são apresentadas as exigências de proteína metabolizável (PM), calculadas conforme

R. Bras. Zootec., v.31, n.3, p.1273-1285, 2002 
Tabela 6 - Parâmetros das equações de regressão do logaritmo dos conteúdos de proteína $(\mathrm{kg})$, gordura (kg) e energia (Mcal) no corpo vazio, em função do logaritmo do peso de corpo vazio $(\mathrm{kg})$ de bovinos F1 Limousin $x$ Nelore, e os respectivos coeficientes de determinação $\left(r^{2}\right)$, para os diferentes níveis de concentrado na dieta, e em conjunto

Table 6 - Parameters of logarithm regression equations of protein $(\mathrm{kg})$, fat $(\mathrm{kg})$ and energy (Mcal) in empty body, as function of empty body weight $(\mathrm{kg})$ of $\mathrm{F1}$ Limousin $x$ Nellore, and respective coefficients of determination $\left(r^{2}\right)$, for different concentrate levels in the diet, and in overall

\begin{tabular}{|c|c|c|c|}
\hline \multirow{2}{*}{$\begin{array}{l}\text { Níveis de } \\
\text { concentrad } \\
(\%) \\
\text { Concentrate } \\
\text { levels }\end{array}$} & \multicolumn{2}{|c|}{$\begin{array}{c}\text { Parâmetros } \\
\text { Parameters }\end{array}$} & \multirow[t]{2}{*}{$\mathrm{r}^{2}$} \\
\hline & $\begin{array}{l}\text { Intercepto (a) } \\
\text { Intercept }\end{array}$ & $\begin{array}{c}\text { Coeficiente (b) } \\
\text { Coefficient }\end{array}$ & \\
\hline & & $\begin{array}{l}\text { Proteína }(\mathrm{kg}) \\
\text { Protein }\end{array}$ & \\
\hline 25 & $-0,356597$ & 0,877599 & 0,95 \\
\hline 37,5 & $-0,446893$ & 0,914958 & 0,96 \\
\hline 50 & $-0,372986$ & 0,884348 & 0,97 \\
\hline 62,5 & $-0,397419$ & 0,894576 & 0,97 \\
\hline 75 & $-0,408869$ & 0,899410 & 0,97 \\
\hline Conjunto & $-0,397954$ & 0,894743 & 0,97 \\
\hline
\end{tabular}

Overall

\begin{tabular}{lccc}
25 & $-2,90920$ & 1,80137 & 0,85 \\
37,5 & $-2,70084$ & 1,71580 & 0,85 \\
50 & $-3,13943$ & 1,89722 & 0,89 \\
62,5 & $-3,21843$ & 1,92983 & 0,89 \\
75 & $-3,22771$ & 1,93326 & 0,90 \\
Conjunto & $-3,06025$ & 1,86401 & 0,88 \\
Overall & & \\
\multicolumn{3}{c}{ Energia (Mcal) } \\
25 & $-0,508413$ & Energy \\
37,5 & $-0,430398$ & 1,35697 & 0,95 \\
50 & $-0,641322$ & 1,32515 & 0,96 \\
62,5 & $-0,705955$ & 1,41241 & 0,97 \\
75 & $-0,711749$ & 1,43921 & 0,96 \\
Conjunto & $-0,612392$ & 1,44138 & 0,97 \\
Overall & & 1,40019 & 0,96 \\
\hline
\end{tabular}

metodologia proposta pelo NRC (1996), utilizando-se os valores referentes às exigências líquidas de proteína para ganho de peso, relativos aos dados em conjunto. Como pode ser observado, as exigências de PM para mantença (PMm) aumentaram com a elevação do $\mathrm{PV}$, o que era esperado, já que as exigências protéicas para mantença são função do PV. Para as exigências de PM para ganho (PMg), para animais com PCVZ acima de $300 \mathrm{~kg}$, foi utilizada uma eficiência de utilização fixa de $49,2 \%$, e os valores apresentaram o mesmo comportamento verificado para as respectivas exigências líquidas, ou seja, reduziram com o aumento do PV. Utilizou-se a seguinte equação para o cálculo da eficiência de utilização da PM para ganho para animais com menos de $300 \mathrm{~kg}$ de PCVZ: Eficiência $=(83,4-(0,114 \times$ PCVZ $))$, segundo Ainslie et al. (1993). Para um bovino não-castrado, pesando $450 \mathrm{~kg}$ de $\mathrm{PV}$ e ganhando $1 \mathrm{~kg}$ de $\mathrm{PV} / \mathrm{dia}$, a exigência de PMé de $758 \mathrm{~g} / \mathrm{dia}, 18,6 \%$ maior que a recomendada pelo NRC (1996) para animais taurinos castrados e 13,2\% superior à encontrada por Ferreira et al. (1999) para mestiços F1 Simental x Nelore não-castrados.

A partir das exigências de PM, apresentadas na Tabela 8, e utilizando-se o protocolo recomendado pelo NRC (1996) para conversão das exigências totais de PM em exigências de proteína bruta (PB), foram calculadas as exigências diárias totais de $\mathrm{PB}$ e as exigências de proteína degradada e não-degradada no rúmen (Tabela 9), utilizando-se o consumo médio de nutrientes digestíveis totais (NDT) de $12,99 \mathrm{~g} / \mathrm{kg}$ de PCVZ. A PMg, por kg de PCVZ, foi corrigida para ganho de PV, multiplicando-se pelo fator 1,02, obtido neste experimento.

A equação obtida para descrever a relação entre a energia retida (ER), em Mcal, e o ganho diário de PCVZ (GDPCVZ), em kg, para determinado PCVZ,

Tabela 7 - Exigências líquidas de proteína (g) e energia (Mcal), por kg de GPCVZ, e conteúdo de gordura no ganho de peso de corpo vazio ( $\mathrm{g} / \mathrm{kg}$ GPCVZ) de bovinos F1 Limousin x Nelore, em função do peso vivo (PV) ou do PCVZ Table 7 - Net requirements of protein (g) and energy (Mcal), in $\mathrm{kg} E B W$, and fat content in empty body weight gain (g/kg EBW) of F1 Limousin x Nellore bulls, as function of live weight (LW) or EBW

\begin{tabular}{|c|c|c|c|c|}
\hline \multirow{3}{*}{$\begin{array}{l}\mathrm{PV}(\mathrm{kg}) \\
L W(\mathrm{~kg})\end{array}$} & \multirow{3}{*}{$\begin{array}{c}\operatorname{PCVZ}(\mathrm{kg}) \\
E B W(\mathrm{~kg})\end{array}$} & \multicolumn{2}{|c|}{$\begin{array}{c}\text { Exigências } \\
\text { Requirements }\end{array}$} & \multirow{3}{*}{$\begin{array}{l}\text { Conteúdo de gordura } \\
(\mathrm{g} / \mathrm{kg} \mathrm{GPCVZ}) \\
\text { Fat content }(\mathrm{g} / \mathrm{kg} E B W)\end{array}$} \\
\hline & & $\begin{array}{c}\text { Proteína } \\
\text { (g/kg GPCVZ) }\end{array}$ & $\begin{array}{c}\text { Energia } \\
\text { (Mcal/kg GPCVZ) }\end{array}$ & \\
\hline & & Protein $(\mathrm{g} / \mathrm{kg} E B W)$ & Energy (Mcal/kg EBW) & \\
\hline 300 & 269,04 & 198,60 & 3,21 & 203,98 \\
\hline 350 & 313,89 & 195,41 & 3,41 & 233,04 \\
\hline 400 & 358,73 & 192,68 & 3,60 & 261,54 \\
\hline 450 & 403,57 & 190,31 & 3,77 & 289,56 \\
\hline 500 & 448,41 & 188,21 & 3,94 & 317,15 \\
\hline
\end{tabular}

\footnotetext{
R. Bras. Zootec., v.31, n.3, p.1273-1285, 2002
} 
Tabela 8 - Exigências de proteína metabolizável para mantença $(\mathrm{PMm})$ e ganho $(\mathrm{PMg}) \mathrm{de}$ $1 \mathrm{~kg}$ de PCVZ (g/kg GPCVZ) de bovinos F1 Limousin x Nelore, em função do peso vivo (PV) ou do PCVZ

Table 8 - Requirements of metabolizable protein for maintenance (MPm) and for gain (MPg) of $1 \mathrm{~kg} \mathrm{EBW} \mathrm{(g/kg} \mathrm{EBW)} \mathrm{of} \mathrm{F1} \mathrm{Limousin} \mathrm{x} \mathrm{Nellore} \mathrm{bulls,} \mathrm{as} \mathrm{function} \mathrm{of} \mathrm{live} \mathrm{weight} \mathrm{(LW)}$ or $E B W$

\begin{tabular}{|c|c|c|c|}
\hline $\begin{array}{l}\mathrm{PV}(\mathrm{kg}) \\
L W(\mathrm{~kg})\end{array}$ & $\begin{array}{l}\operatorname{PCVZ}(\mathrm{kg}) \\
E B W(\mathrm{~kg})\end{array}$ & $\begin{array}{c}\text { Exigência de } \mathrm{PMm}^{1} \\
\text { MPm requirement }\end{array}$ & $\begin{array}{c}\text { Exigência de } \mathrm{PMg}^{2} \\
\text { MPg requirement }\end{array}$ \\
\hline 300 & 269,04 & 273,92 & 376,65 \\
\hline 350 & 313,89 & 307,49 & 397,17 \\
\hline 400 & 358,73 & 339,88 & 391,63 \\
\hline 450 & 403,57 & 371,27 & 386,80 \\
\hline 500 & 448,41 & 401,80 & 382,54 \\
\hline
\end{tabular}

conforme recomendação do NRC (1984 e 1996), a partir dos dados do presente trabalho, foi a seguinte: $\mathrm{ER}=0,038 \times \mathrm{PCVZ}^{0,75} \times \mathrm{GDPCVZ}^{0,9896}$

$$
\left(\mathrm{R}^{2}=0,75\right)
$$

A partir desta equação, a ER de um animal com GDPCVZ igual a $1 \mathrm{~kg}$ e PV de $500 \mathrm{~kg}$ é de $3,72 \mathrm{Mcal} /$ dia. A substituição destes valores na equação desenvolvida por Garrett (1980), utilizando animais taurinos castrados, e adotada pelo NRC (1984, 1996): $\mathrm{ER}=0,0635 \times \mathrm{PCVZ}^{0,75} \times \mathrm{GDPCVZ}^{1,097}$, resultou em um valor de ER de 5,07 Mcal/dia, subtraindo-se $18 \%$ das exigências energéticas de bovinos castrados, cujas exigências energéticas foram maiores que as dos animais não-castrados.

Seguindo a mesma metodologia, ou seja, análise de regressão da retenção de energia, em função do PCVZ e do GDPCVZ, Ferreira et al. (1999), trabalhando com bovinos F1 Simental x Nelore não-castrados, obtiveram a seguinte equação:

$$
\begin{gathered}
\mathrm{ER}=0,042 \times \mathrm{PCVZ}^{0,75} \times \mathrm{GDPCVZ}^{1,2257} \\
\left(\mathrm{r}^{2}=0,94\right)
\end{gathered}
$$

Utilizando a equação descrita por Ferreira et al. (1999), para o mesmo animal, a ER seria de 4,09 Mcal/dia.

O valor de ER obtido com a equação do presente trabalho foi semelhante ao encontrado com a equação de Ferreira et al. (1999), que também utilizaram bovinos mestiços não-castrados. Entretanto, foi 26,6\% inferior à ER observada quando se utilizou a equação proposta pelo NRC $(1984,1996)$, provavelmente devido às menores quantidades de gordura entremeada (marmoreio) e gordura total depositadas em animais mestiços, em relação à maioria dos taurinos.

Pela regressão do logaritmo da produção diária de calor (PC), em função do consumo diário de energia metabolizável (CEM), em kcal/PCVZ ${ }^{0,75}$, foi obtida a equação $\log \mathrm{PC}=1,883+0,0015 \mathrm{CEM}$ $\left(\mathrm{r}^{2}=0,78\right)$, cujo antilog do intercepto indicou o valor de $76,36 \mathrm{kcal} / \mathrm{PCVZ}^{0,75} /$ dia como exigência de energia líquida para mantença (ELm) dos animais. A partir desta equação, obteve-se o consumo de EM no equilíbrio, ou seja, o ponto no qual a PC foi igual ao

Tabela 9 - Exigências de proteína degradada no rúmen (PDR), proteína não-degradável no rúmen (PNDR) e proteína bruta (PB), em g/dia, de bovinos F1 Limousin x Nelore, em função do peso vivo (PV) ou do PCVZ, para mantença e ganho de $1 \mathrm{~kg}$ de PV, e consumos médios de NDT ( $\mathrm{kg} / \mathrm{dia})$

Table 9 - Requirements of rumen degradable protein (RDP), rumen undegradable protein (RUP) and crude protein (CP), in kg/day,

\begin{tabular}{|c|c|c|c|c|c|}
\hline $\begin{array}{l}\mathrm{PV}(\mathrm{kg}) \\
L W(k g)\end{array}$ & $\begin{array}{c}\text { PCVZ }(\mathrm{kg}) \\
E B W(\mathrm{~kg})\end{array}$ & $\begin{array}{l}\text { PDR } \\
R D P\end{array}$ & $\begin{array}{l}\text { PNDR } \\
N D P R\end{array}$ & $\begin{array}{l}\mathrm{PB} \\
C P\end{array}$ & $\begin{array}{c}\operatorname{NDT}(\mathrm{kg} / \mathrm{dia}) \\
\operatorname{TDN}(\mathrm{kg} / \mathrm{d})\end{array}$ \\
\hline 300 & 269,04 & 454,23 & 459,25 & 913,48 & 3,49 \\
\hline 350 & 313,89 & 529,94 & 466,81 & 996,74 & 4,08 \\
\hline 400 & 358,73 & 605,64 & 439,66 & 1045,31 & 4,66 \\
\hline 450 & 403,57 & 681,35 & 412,19 & 1093,53 & 5,24 \\
\hline 500 & 448,41 & 757,05 & 384,34 & 1141,39 & 5,82 \\
\hline
\end{tabular}
of F1 Limousin x Nellore bulls, as function of live weight (LW) or EBW, for maintenance and gain of $1 \mathrm{~kg} L W$, and TDN intake $(\mathrm{kg} / \mathrm{d})$

R. Bras. Zootec., v.31, n.3, p.1273-1285, 2002 
CEM, de 112,89 kcal/PCVZ ${ }^{0,75} /$ dia. Fazendo-se o cálculo da exigência de ELm dos animais deste experimento, em função do $\mathrm{PV}$, obteve-se o valor de $\mathrm{ELm}=70,37 \mathrm{kcal} / \mathrm{kg}^{0,75} / \mathrm{dia}$.

O valor obtido para exigência de ELm $\left(76,36 \mathrm{kcal} / \mathrm{PCVZ}^{0,75} / \mathrm{dia}\right)$ está próximo ao de $77 \mathrm{kcal} / \mathrm{kg}^{0,75} / \mathrm{dia}$, obtido por Lofgreen \& Garrett (1968), para machos castrados e novilhas de raças taurinas. Contudo, para machos não-castrados, o NRC (1996) considera as exigências de ELm 15\% maiores que as de machos castrados e novilhas, ou seja, de $88,55 \mathrm{kcal} / \mathrm{kg}^{0,75}$, bastante superior à encontrada neste trabalho para animais mestiços, que são menos exigentes que os taurinos, pois os zebuínos têm, de acordo com o NRC (1996), exigências 10\% menores que os taurinos, ou seja, $79,70 \mathrm{kcal} / \mathrm{kg}^{0,75} / \mathrm{dia}$. Portanto, os animais do presente experimento apresentaram exigências de ELm mais próximas às de zebuínos em relação às de taurinos. A ELm observada foi menor que a relatada por Teixeira (1984), para mestiços $1 / 2$ e $3 / 4$ Holandês x Zebu, porém, foi maior que a dos mestiços $1 / 2$ Marchigiana $x$ Nelore $e$ $1 / 2$ Limousin $x$ Nelore do experimento de Pires et al. (1993), de 67,92 e 68,03 kcal/PCVZ ${ }^{0,75} /$ dia, e que as dos F1 Holandês x Nelore utilizadas por Freitas (1995), de 59,77 kcal/ $/ \mathrm{kg}^{0,75} /$ dia.

Para os dados do presente trabalho, as exigências líquidas diárias de energia para mantença, para animais com PV de 300, 350, 400, 450 e $500 \mathrm{~kg}$, são apresentadas na Tabela 10. Estes resultados foram maiores que os encontrados por Pires et al. (1993), para mestiços F1 Marchigiana x Nelore e Limousin x Nelore, de 4,41; 4,94; 5,47; 5,98; e 6,47 Mcal/dia, respectivamente, para $300,350,400,450$ e $500 \mathrm{~kg}$ $\mathrm{PV}$, e que os relatados por Freitas (1995) para animais bimestiços, F1 Holandês x Nelore e bubalinos,

Tabela 10 - Exigências líquidas diárias de energia para mantença de bovinos F1 Limousin x Nelore, em função do peso vivo (PV) ou do PCVZ

Table 10 - Daily net requirement of maintenance energy for F1 Limousin x Nellore bulls, as function of live weight (LW) or EBW

\begin{tabular}{lcc}
\hline $\mathrm{PV}(\mathrm{kg})$ & $\mathrm{PCVZ}(\mathrm{kg})$ & $\mathrm{ELm}(\mathrm{Mcal} / \mathrm{dia})$ \\
$L W(\mathrm{~kg})$ & $E B W(\mathrm{~kg})$ & $N E m($ Mcal $/ \mathrm{d})$ \\
\hline
\end{tabular}

\begin{tabular}{lll}
300 & 269,04 & 5,07 \\
350 & 313,89 & 5,69 \\
400 & 358,73 & 6,29 \\
450 & 403,57 & 6,88 \\
500 & 448,41 & 7,44 \\
\hline
\end{tabular}

R. Bras. Zootec., v.31, n.3, p.1273-1285, 2002 em conjunto, de 4,74; 5,24; 5,72; e 6,19 Mcal/dia, para $350,400,450$ e $500 \mathrm{~kg}$ PV, respectivamente. Todavia, foram inferiores aos verificados por Estrada et al. (1997), para mestiços F1 Nelore x Angus e F1 Nelore x Holandês não-castrados, para a faixa de PV de 350 a $500 \mathrm{~kg}$, de 7,60 a 9,75 Mcal/dia.

\section{Conclusões}

As exigências de energia líquida para ganho de peso de animais F1 Limousin x Nelore não-castrados, em Mcal $/ \mathrm{kg}$, podem ser obtidas pela equação: $\mathrm{ER}=0,038 \times \mathrm{PCVZ}^{0,75} \times \mathrm{GDPCVZ}^{0,9896}$.

A exigência energética para mantença foi de $76,36 \mathrm{kcal} / \mathrm{PCVZ}^{0,75}$, para animais $\mathrm{F} 1$ Limousin $\mathrm{x}$ Nelore não-castrados.

A exigência líquida de proteína para ganho de peso de mestiços F1 Limousin x Nelore não-castrados, em g/dia, pode ser obtida pela equação: $\mathrm{PR}=174,14524 \times$ GPVJ.

\section{Literatura Citada}

AGRICULTURAL AND FOOD RESEARCH COUNCIL AFRC. Energy and protein requeriments of ruminants. Wallingford: CAB International, 1993. 159p.

AGRICULTURAL RESEARCH COUNCIL - ARC. The nutrient requirements of ruminants livestock. London: CAB International, 1980. 351p.

AINSLIE, S.J.; FOX, D.G.; PERRY, T.C. et al. Predicting amino acid adequacy of diets fed to Holstein steers. Journal of Animal Science, v.71, p.1312-1319, 1993.

ALLEN, M.S. Physical constraints on voluntary intake of forages by ruminants. Journal of Animal Science, v.74, n.12, p.3063-3075, 1996.

ASSOCIATION OFFICIAL ANALYTICAL CHEMISTS AOAC. Official methods of analysis. 13.ed. Washington, D.C.: AOAC, 1980. 1015p.

BERG, R.T.; BUTTERFIELD, R.M. New concepts of cattle growth. New York: Sydney University, 1976. 240p.

CARDOSO, R.C.; VALADARES FILHO, S.C.; SILVA, J.F.C. et al. Consumo e digestibilidades aparentes totais e parciais de rações contendo diferentes níveis de concentrado, em novilhos F1 Limousin x Nelore. Revista Brasileira de Zootecnia, v.29, n.6, p.1832-1843, 2000.

CSIRO. Feeding standards for Australian livestock. Ruminants. Melbourne: CSIRO, 1990. 266p.

DIAS, H.L.C.; VALADARES FILHO, S.C.; SILVA, J.F.C. et al. Consumo e digestões totais e parciais em novilhos F1 Limousin $\mathrm{x}$ Nelore alimentados com dietas contendo cinco níveis de concentrado. Revista Brasileira de Zootecnia, v.29, n.2, p.545-554, 2000.

ENSMINGER, M.E.; OLDFIELD, J.E.; HEINEMANN, W.W. Feeds \& nutrition. 2.ed. Clovis: Ensminger Publishing Company, 1990. p.19-46.

ESTRADA, L.H.C.; FONTES, C.A.A.; JORGE, A.M. et al. Exigências nutricionais de bovinos não-castrados em confinamento. 1. Conteúdo corporal e exigências líquidas de 
proteína e energia para ganho de peso. Revista Brasileira de Zootecnia, v.26, n.3, p.575-583, 1997.

FERREIRA, M.A.; VALADARES FILHO, S.C.; SILVA, J.F.C. et al. Composição corporal e exigências líquidas de proteína e energia para ganho de peso de bovinos F1 Simental x Nelore. Revista Brasileira de Zootecnia, v.28, n.2, p.352-360, 1999.

FONTES, C.A.A. Composição corporal, exigências líquidas de nutrientes para ganho de peso e desempenho produtivo de animais zebuínos e mestiços europeu-zebu. Resultados experimentais. In: SIMPÓSIO INTERNACIONAL SOBRE EXIGÊNCIAS NUTRICIONAIS DE RUMINANTES, 1995, Viçosa. Anais... Viçosa: Universidade Federal de Viçosa, 1995. p.419-455.

FREITAS, J.A. Composição corporal e exigência de energia e proteína de bovinos (zebuínos e mestiços) e bubalinos não castrdos, em confinamento. Viçosa, MG: Universidade Federal de Viçosa, 1995. 132p. Dissertação (Mestrado em Zootecnia) - Universidade Federal de Viçosa, 1995.

GARRETT, W.N. Factors influencing energetic efficiency of beef production. Journal of Animal Science, v.51, n.6, p.1434-1440, 1980.

GRANT, A.L.; HELFERICH, W.G. An overview of growth. In: PEARSON, A.M.; DUTSON, T.R. (Eds.). Growth regulation in farm animals. London: Elsevier Applied Science, 1991. p.1-15.

HALL, M.B. Recent advances in non-NDF carbohydrates for the nutrition of lactating cows. In: SIMPÓSIO INTERNACIONAL EM BOVINOCULTURA DE LEITE: NOVOS CONCEITOS EM NUTRIÇÃO, 2., 2001, Lavras. Anais... Lavras: Universidade Federal de Lavras, 2001. p.139-148.

HANKINS, O.G.; HOWE, P.E. Estimation of the composition of beef carcasses and cuts. Washington, D.C.: USDA. (Technical Bulletin - USDA, 926), 1946.

INSTITUT NATIONAL DE LA RECHERCHE AGRONOMIQUE - INRA. In: JARRIGE, R. (Ed.) Alimentation des bovines, ovines, et caprines. Paris: INRA, 1988.

LOFGREEN, G.P.; GARRETT, W.N.A. A system for expressing net energy requirements and feed values for growing and finishing beef cattle. Journal of Animal Science, v. 27, n.3, p.793-806, 1968.

McDONALD, P.; EDWARDS, R.A.; GREENHALGH, J.F.D. et al. Animal nutrition. 5.ed. Singapore: Longman, 1995. $607 \mathrm{p}$.

NATIONAL RESEARCH COUNCIL - NRC. Nutrient requirement of beef cattle. 6 .ed. Washington, D.C.: National Academy Press, 1984. 90p.

NATIONAL RESEARCH COUNCIL - NRC. Nutrient requirement of beef cattle. 7.ed. Washington, D.C.: National Academy Press, 1996. 242p.

NATIONAL RESEARCH COUNCIL - NRC. Predicting feed intake of food-producing animals. Washington, D.C.: National Academy Press, 1987. 85p.
OSPINA, H.; PRATES, E.R. Efeito de quatro níveis de oferta de feno sobre o consumo de nutrientes digestíveis por bezerros. Revista Brasileira de Zootecnia, v.27, n.4, p.809-814, 1998.

PIRES, C.C.; FONTES, C.A.A.; GALVÃO, J.G. et al. Exigências nutricionais de bovinos de corte em acabamento. 1. Composição corporal e exigências de proteínas para ganho de peso. Revista da Sociedade Brasileira de Zootecnia, v.22, n.1, p.110-120, 1993.

REGAZZI, J.A. Teste para verificar a identidade de modelos de regressão. Pesquisa Agropecuária Brasileira, v.31, n.1, p.1-17, 1996.

ROBELIN, J.; GEAY, Y. Body composition of cattle as affected by physiological status, breed, sex and diet. In: GILCHRIST, F.M.C.; MACKIE, R.I. (Eds.). Herbivore nutrition in the subtropical and tropics. Johannesburg: Science Press, 1984. p.525-547.

SILVA, D.J. Análise de alimentos (métodos químicos e biológicos). Viçosa, MG: Universidade Federal de Viçosa, 1990. 165 p.

SILVA, F.F.; VALADARES FILHO, S.C.; ÍTAVO, L.C.V. et al. Requisitos protéicos e energéticos de bovinos Nelore nãocastrados. In: REUNIÃO ANUAL DA SOCIEDADE BRASILEIRA DE ZOOTECNIA, 38., 2001, Piracicaba. Anais... Piracicaba: Sociedade Brasileira deZootecnia, 2001.p.937-939.

SMUTS, D. The relation between the basal metabolism and the endogenous nitrogen metabolism, with particular reference to the maintenance requirement of protein. Journal Nutrition, v.9, p.403-433, 1935.

TEIXEIRA, J.C. Exigências de energia e proteína, composição e área corporal e principais cortes da carcaça em seis grupos genéticos de bovídeos. Viçosa, MG: Universidade Federal de Viçosa, 1984. 94p. Tese (Doutorado em Zootecnia) Universidade Federal de Viçosa, 1984.

UNIVERSIDADE FEDERAL DE VIÇOSA - UFV. SAEG Sistema de análises estatísticas e genéticas. Viçosa, MG. 1995. (Apostila)

VÉRAS, A.S.C. Consumo, digestibilidade, composição corporal e exigências nutricionais de bovinos Nelore alimentados com rações contendo diferentes níveis de concentrado. Viçosa, MG: Universidade Federal de Viçosa, 2000. 192p. Tese (Doutorado em Zootecnia) - Universidade Federal de Viçosa, 2000.

WILKERSON, V.A.; KLOPFENSTEIN, T.J.; BRITTON, R.A. et al. Metabolizable protein and amino acid requirements of growing beef cattle. Journal of Animal Science, v.71, p.2777-2784, 1993. 